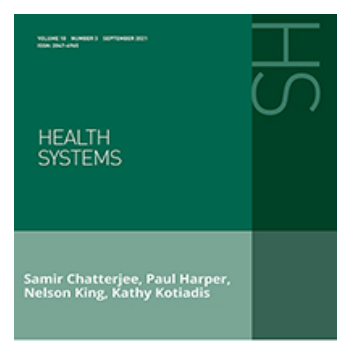

Health Systems

\title{
A Systems-Based Framework for Immunisation System Design: Six Loops, Three Flows, Two Paradigms
}

\section{Catherine Decouttere, Nico Vandaele, Kim De Boeck \& Stany Banzimana}

To cite this article: Catherine Decouttere, Nico Vandaele, Kim De Boeck \& Stany Banzimana (2021): A Systems-Based Framework for Immunisation System Design: Six Loops, Three Flows, Two Paradigms, Health Systems, DOI: 10.1080/20476965.2021.1992300

To link to this article: https://doi.org/10.1080/20476965.2021.1992300

\section{ช} Group.

\section{Published online: 28 Oct 2021.}

Submit your article to this journal $\llbracket$

Q View related articles $₫$

View Crossmark data $\asymp$ 


\title{
A Systems-Based Framework for Immunisation System Design: Six Loops, Three Flows, Two Paradigms
}

\author{
Catherine Decouttere ${ }_{(D)}{ }^{a}$, Nico Vandaele ${ }^{a}$, Kim De Boeck ${ }^{\mathrm{a}}$ and Stany Banzimana ${ }^{\mathrm{b}}$ \\ aCentre for Access-To-Medicines (ATM) at Katholieke Universiteit Leuven, Leuven, Belgium; bUniversity of Rwanda, EAC Regional Centre of \\ Excellence for Vaccines, Immunisation and Health Supply Chain Management, Kigali, Rwanda
}

\begin{abstract}
Despite massive progress in vaccine coverage globally, the region of sub-Saharan Africa is lagging behind for Sustainable Development Goal 3 by 2030. Sub-national underimmunisation is part of the problem. In order to reverse the current immunisation system's (IMS) underperformance, a conceptual model is proposed that captures the complexity of IMSs in low- and middle-income countries (LMICs) and offers directions for sustainable redesign. The IMS model was constructed based on literature and stakeholder interaction in Rwanda and Kenya. The model assembles the paradigms of planned and emergency immunisation in one system and emphasises the synchronised flows of vaccinee, vaccinator and vaccine. Six feedback loops capture the main mechanisms governing the system. Sustainability and resilience are assessed based on loop dominance and dependency on exogenous factors. The diagram invites stakeholders to share their mental models and. The framework provides a systems approach for problem structuring and policy design.
\end{abstract}

ARTICLE HISTORY

Received 27 December 2019 Accepted 28 September 2021

\section{KEYWORDS}

System design; immunisation; sub-saharan africa; resilience; sustainability; problem structuring

\section{Introduction}

Since the introduction of routine childhood immunisation in low-income-countries (LICs) in 1974 as the Expanded Program on Immunisation (EPI), a spectacular global decrease in neonatal mortality rate (NMR) and under-five mortality rate (U5MR) has been observed. However, the world-wide diphtheria-tetanuspertussis third dose (DTP3) national immunisation coverage level has nearly stagnated since 2009 at $85 \%$. In 2018, the DTP3 coverage in the African continent was only $76 \%$ (United Nations Inter-agency Group for Child Mortality Estimation, 2018; WHO-Unicef, 2019), which is well below the 2015 target of the Global Vaccine Action Plan (GVAP) of $90 \%$.

At the sub-national level, the 2020 GVAP target of 80\% DTP3 coverage in every district seems unlikely for most sub-Saharan (SSA) countries. Although highquality sub-national indicators are not always readily available for SSA, estimates of U5MR based on different sources show significant variations and point out that local conditions play a more critical role than administrative boundaries and that major health inequities exist which penalise the poor people in rural areas and urban slums (Ndwandwe et al., 2018). According to a Sustainable Development Goal (SDG) baseline analysis for NMR and U5MR in Africa, many localities and geographical regions will need specifically targeted interventions if they are to reach the health-related SDG targets (Golding et al., 2017).
According to the Lancet Commission on the future of health in SSA (Agyepong et al., 2017), new health systems should focus on local context, peoplecentredness and prevention. Similarly, both Immunisation Agenda 2030 (IA2030) and the GAVI 5.0 plan urge for both inclusive systems, viewing immunisation from a life-course perspective (GAVI The Vaccine Alliance, 2019; WHO, 2020) and for resilient systems, resistant to both chronic stress and acute shocks, and that show adaptability systems (Barasa et al., 2018).

Some factors of the immunisation system (IMS), such as the vaccine supply chain, have been intensively modelled to identify key areas of intervention in the particular subsystems (De Boeck et al., 2020; Duijzer et al., 2018; Haidari et al., 2017; Lemmens et al., 2016; Sarley et al., 2017; Wedlock et al., 2018; Yadav, 2015). In addition, the impact of the vaccine supply chain performance on the reported IMS performance was modelled (Gooding et al., 2019). On a separate line, human behavioural impact such as the role of vaccine hesitancy has been studied (Larson et al., 2018). Systems thinking and implementation research, applied to low - and middle-income countries' (LMICs) health systems, highlighted the power of taking a system's perspective to understand complexity, adaptive behaviour and underlying mechanisms to missed opportunities to vaccinate (Adamu et al., 2019; Ozawa et al., 2016; Remme et al., 2010; Rwashana et al., 2016; WHO | The Alliance for Health Policy 
and Systems Research (AHPSR), 2019). Dynamic simulation models and health economic decision frameworks further stress the importance of transdisciplinary phenomena, capturing delays and non-linear behaviour for decision-making (Auping et al., 2017; Baltussen et al., 2017; Gonçalves, 2011; Lee et al., 2017; Rouwette et al., 2009).

However, the combined, dynamic and long-term effect of these interacting actors on national IMS performance and health-related SDGs is not fully understood.

The aim of this paper is, therefore (1) to develop a systems-inspired framework, which links system actors to national-level IMS performance and health-related SDGs and (2) to support stakeholders in defining design directions for a resilient and sustainable IMS.

\section{Materials and methods}

In order to develop this IMS model, a human-centred design and systems thinking approach was taken. Principles and tools such as causality and systems diagrams were applied to LMICs' IMS to conceptually represent delays, feedback, and to identify key leverage points. Such an IMS diagram can be applied to align and refine the mental models of stakeholders to enable them to identify underlying mechanisms and potential avenues for system redesign (Adam \& de Savigny, 2012; Kopainsky et al., 2017; Sterman, 2000). System interventions are most effective when they are acting on system leverage points (Meadows \& Wright, 2008). The identification of these leverage points on a systems diagram and the orientation in which to direct them is facilitated by combining the expertise of stakeholders and systems modellers. In addition to the IMS diagram, a framework for intervention scenario building was generated, based on the five-level "Intervention-Level Framework" (Malhi et al., 2009).

\subsection{Model definition}

Starting from the aim of the paper, the purpose and scope of the model and the intended users and their requirements were defined. The purpose of the conceptual model is to fit into a broader health system design process, such as the five-step framework for system design, the iterative system dynamics modelling process, a community-based system dynamics project, or a human-centred design process (Decouttere et al., 2016; Hovmand, 2014; Sterman, 2000).

The scope of the model was a national IMS of an African country, incorporating all the resources, challenges and contextual background with the goal to achieve the immunisation-related SDGs by 2030 . Acting as a major decision level for EPI, we considered the national-level decision makers as intended users. Requirements for the conceptual model were defined with two aims. First, to clarify system actors' contribution, the framework must invite stakeholders to share their mental models with other stakeholders. For example, the framework helps an EPI vaccine procurement officer at the national level, an EPI nurse in a health centre (HC) and a community leader to understand how they are connected within the system by the vaccines propagating through the supply chain, the number of people living in the community and the vaccination coverage targets. In addition, the framework must enable the stakeholders to build on available knowledge and contextual elements, such as local epidemiology and the emergence of vaccinepreventable disease (VPD) outbreaks. Second, to support stakeholders in system design, the framework must enable stakeholders to identify underlying mechanisms across disciplines. Building further on the previous example, the framework should reveal to the procurement officer, the nurse, and the community leader some of the causes of previously observed missed-opportunities-to-vaccinate (MOVs), such as a vaccine out-of-stock, and its underlying mechanism. It should also inspire stakeholders to intervene at leverage points, such as implementing and applying electronic health data management at the HCs, without introducing other problems.

Based on their immunisation performance, their current and future challenges, and data availability within an existing collaboration opportunity, the Rwandan and Kenyan IMS were selected. Background data were gathered from policy documents such as the "comprehensive Multi-Year Plan for Immunisation" (cMYPs). The system boundary was set at the immunisation system and did not extend to other preventive health programmes such as nutritional programmes or family planning.

\subsection{Model development}

The process that was applied to develop the IMS conceptual model (Figure 1) consists of iterative cycles of stakeholder engagement in the stages of exploration, conceptualisation, testing and validation, which took place between 2016 and 2019. An overview of the stakeholder engagement activities and methodologies applied, including interviews, workshops, and group model building sessions, is provided in Table 1. Stakeholder interaction throughout the model development process led to 27 interviews in Rwanda, Kenya, and Europe, and four workshops with a total of 63 participants. Over a period of 5 years (2015-2019), starting from immunisation coverage data and immunisation plans, a basic structure was created by connecting insights from different fields. Although 


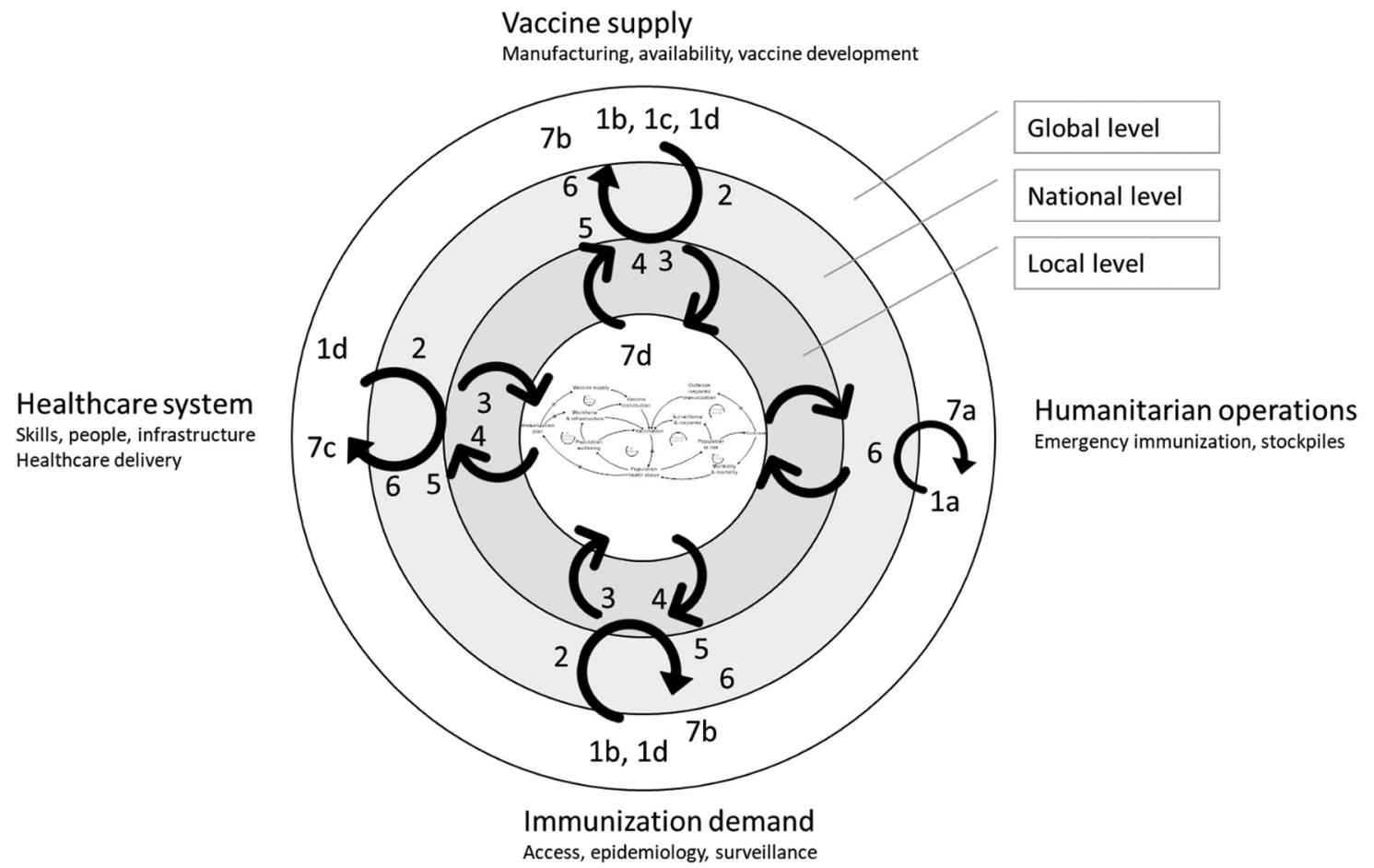

Figure 1. Map of interaction activities with stakeholders for the development and validation of the systems diagram. The numbers 1a,b,c to 7 a,b,c refer to the stakeholder engagement activities listed in Table 1, e.g., 1a is a stakeholder interview with Médecins sans Frontières in Brussels. The concentric rings, with the resulting IMS diagram in the centre, indicate the system levels at which the stakeholder operates, or has his or her expertise. The four outer orientations (Vaccine supply, Humanitarian operations, Immunisation demand and Healthcare system) refer to the main background of the stakeholders. One activity can appear at different locations, for example, a group model building session with stakeholders with different backgrounds. The grey arrows show the iterative, multi-level knowledge build-up while the black arrows indicate how this knowledge flows to and from the IMS diagram under construction.

experts tended to initially stay within their own field of expertise, such as the vaccine supply chain, they easily directed to connections with other actors, such as health system human resources or vaccine campaign planning, which triggered consecutive interviews in a multidisciplinary landscape. We observed that phenomena that are managed by different programmes, such as planned immunisation and outbreak response, were often considered as separate worlds by experts. Workshops with participants from the national and subnational levels of the immunisation system of six East-African countries proved to be a powerful means of mental model elicitation. By building a national IMS diagram for each country during the workshops, a discussion of perceived and real differences between national IMSs arose. In addition, behavioural mechanisms and cultural contexts were clarified, which explain human decision-making and impact system performance. These all led to valuable insights into the construction of the IMS diagram. Furthermore, these workshops triggered participants to come up with resourceful suggestions for IMS improvement, as they hosted the combined views of different vertical levels (national- subnational), different fields of expertise (logistic, pharmacology) and different socio-cultural contexts. For example, explaining reasons for missed opportunities to vaccinate, the impact of crosscutting actors such as target population behaviour and data availability was clarified in different contexts.

\subsection{Model application}

The model was applied and validated in group model building sessions. Next, the model served as a structure to assess sustainability and resilience of the IMS at the national level. Finally, the IMS diagram was applied to two settings in Rwanda to clarify the causes of local immunisation performance.

\section{Results}

\subsection{The IMS diagram}

The IMS diagram is built as a systems diagram consisting of selected high-level feedback loops between system actors that provide the necessary structure to meet the model requirements as specified in the model definition. 
Table 1. Overview of stakeholder interaction activities that served as input for IMS diagram development. The numbers of the activities (1a to $7 d$ ) listed in this table appear in Figure 1.

\begin{tabular}{|c|c|c|c|c|}
\hline \multicolumn{2}{|c|}{ Interaction type } & \multirow{2}{*}{\multicolumn{2}{|c|}{$\begin{array}{l}\text { Participants, location, } \\
\text { timing } \\
\text { 1a MSF, Brussels } \\
\text { 1b UNICEF, SC division, } \\
\text { Copenhagen } \\
\text { 1 c Vaccine } \\
\text { manufacturers } \\
\text { 1d Donor } \\
\text { organisations } \\
\text { 2015-2019 }\end{array}$}} & Main topics discussed \\
\hline 1 & Exploration global level & & & $\begin{array}{l}\text { Links between Health system development and } \\
\text { humanitarian aid, infrastructure gap, skills retention, } \\
\text { project handover } \\
\text { Vaccine funding, humanitarian mechanisms, vaccine } \\
\text { stockpiles } \\
\text { Health systems strengthening approach UNICEF, GAVI } \\
\text { Improvement potential at interfaces of disciplines, e.g., } \\
\text { vaccine manufacturing \& procurement conditions, } \\
\text { temperature requirements }\end{array}$ \\
\hline 2 & $\begin{array}{l}\text { Mental model elicitation } \\
\text { national } \\
\text { immunisation system }\end{array}$ & Group model building & $\begin{array}{l}\text { Senior and middle EPI } \\
\text { staff national level. } \\
\text { Mixed groups: } \\
\text { Kigali 2016: } \\
22 \text { participants from } \\
\text { Rwanda, Kenya, } \\
\text { Uganda, Tanzania, } \\
\text { South-Sudan } \\
\text { Nairobi 2017: } \\
25 \text { participants from } \\
\text { Rwanda, Kenya, } \\
\text { Uganda, Burundi, } \\
\text { Tanzania, South-Sudan }\end{array}$ & $\begin{array}{l}\text { Stakeholders involved in execution and decision making } \\
\text { Mental model change from Supply Chain to systems } \\
\text { thinking } \\
\text { Policy making in cMYP, immunisation plan } \\
\text { Private sector role and partnerships (logistics) } \\
\text { Sharing views between countries, adapt approach to } \\
\text { country } \\
\text { Financial mechanisms, equity, sustainability, efficiency } \\
\text { Data management and issues, denominator error } \\
\text { Vaccine coverage and health outcomes: delays, } \\
\text { epidemiology } \\
\text { Implementation complexity: new vaccines, eLMIS } \\
\text { Workforce capacity, immunisation integration in health } \\
\text { services }\end{array}$ \\
\hline 3 & $\begin{array}{l}\text { Mental model elicitation } \\
\text { district level }\end{array}$ & $\begin{array}{l}\text { Interviews, observation, } \\
\text { numerical data collection at } \\
\text { DHs }\end{array}$ & $\begin{array}{l}\text { Rwanda: } 2 \text { district } \\
\text { hospitals (2018-2019) } \\
\text { Kenya: } 2 \text { district } \\
\text { hospitals (2018) }\end{array}$ & $\begin{array}{l}\text { Vaccine supply chain, vaccine wastage, ordering process } \\
\text { Outreach planning and funding } \\
\text { Skills and training EPI staff and Community Health } \\
\text { Workers } \\
\text { Diversity between HCs in the district, root causes of } \\
\text { coverage variation } \\
\text { Demand data availability, district coordinating role }\end{array}$ \\
\hline 4 & $\begin{array}{l}\text { Mental model elicitation } \\
\text { local level }\end{array}$ & $\begin{array}{l}\text { Interviews, observations, } \\
\text { numerical data collection at } \\
\text { HCs, outreach, CHWs }\end{array}$ & $\begin{array}{l}\text { Kenya: } 5 \text { health facilities } \\
\text { (2018) } \\
\text { Rwanda: } 5 \text { health } \\
\text { facilities } \\
\text { (2019) }\end{array}$ & $\begin{array}{l}\text { Local vaccine management organisation, vaccine transport } \\
\text { Community health worker, defaulter tracing, disease } \\
\text { case detection } \\
\text { Demand-side determinants, access to HFs } \\
\text { Impact of local problem-solving capacity at HF }\end{array}$ \\
\hline 5 & $\begin{array}{l}\text { Validation national level } \\
\text { IMS model }\end{array}$ & Feedback workshops & $\begin{array}{l}\text { EPI, WHO, implementers } \\
\text { Nairobi 2018, Kigali } \\
2019\end{array}$ & $\begin{array}{l}\text { Data management } \\
\quad \text { Public-Private health services }\end{array}$ \\
\hline 6 & $\begin{array}{l}\text { Validation national level } \\
\text { IMS model }\end{array}$ & Feedback meetings & $\begin{array}{l}\text { EPI, Kigali, } 2019 \\
\quad \text { UNICEF, Kigali, } 2019\end{array}$ & $\begin{array}{l}\text { Financial sustainability } \\
\text { Supply chain redesign, Digital transformation } \\
\text { Disease surveillance, emergency immunisation } \\
\text { (measles, Ebola) } \\
\text { Integration with other preventive HC systems (nutrition, } \\
\text { Primary HC) }\end{array}$ \\
\hline 7 & $\begin{array}{l}\text { Validation and } \\
\text { refinement by } \\
\text { international domain } \\
\text { experts }\end{array}$ & Feedback meetings (2019) & $\begin{array}{l}\text { 7a Academic } \\
\text { anthropologist } \\
\text { 7b Funding } \\
\text { mechanism expert } \\
\text { 7 c Academic Public } \\
\text { Health } \\
\text { 7d Academic systems } \\
\text { expert }\end{array}$ & $\begin{array}{l}\text { Vaccine hesitancy, emergency immunisation } \\
\text { Design thinking, paradigm shift, Innovation } \\
\text { interventions } \\
\text { Sustainable mechanisms, Local contextual approach, } \\
\text { community health } \\
\text { Sustainability and resilient systems, systems levels and } \\
\text { interventions }\end{array}$ \\
\hline
\end{tabular}

The goal of the IMS is captured by SDG3: "Ensure healthy lives and promote well-being for all at all ages "(UN, n.d.). More specifically, the IMS should deliver the SDG3.2 targets on NMR ( $<12 / 1000$ live births) and U5MR ( $<25 / 1000$ live births) by 2030. In line with SDG3, global and national intermediate targets have been set, and programmes for immunisation have been defined: the Global Vaccine Action plan (GVAP), Decade of Vaccines (DoV), disease-specific eradication and elimination programmes, and Immunisation Agenda 2030. Central to the IMS is the strategy of vaccination to ensure health and well-being. The combined effect of vaccination and complementary health-promoting strategies, such as nutrition, is observed in the reduction of U5MR.

\subsubsection{Two paradigms: planned and emergency immunisation}

Following the purpose of the IMS, the implementation is materialised in the National Immunisation Program (NIP) which is based on three pillars: Routine Immunisation (RI), Supplemental Immunisation Activities (SIAs) and surveillance for epidemic-prone diseases. Both RI and SIAs are intended to pro-actively 
prevent VPD cases. However, when disease cases occur, they are detected by the surveillance mechanism, which activates a response mechanism in order to prevent a wider outbreak. If despite the activation of this mechanism, the outbreak reaches a certain scale and the local or national IMS is no longer able to control the health risk, outbreak response immunisation (ORI) can be invoked to comply with International Health Regulations (IHR) to guarantee international health safety (World Health Organization (WHO). (2016). International Health Regulations, 2005; World Health Organization (WHO) \& Centers for Disease Control and Prevention (CDC), 2010). In the aggregated system diagram (Figure 2) Planned and Emergency Immunisation are represented as two complementary pathways in the system and are connected by Vaccination, the common strategy, and Population Health Status, the common goal.Figure 3

At the national level, Planned immunisation is guided annually by the NIP, which defines yearly domestic and donor budgets. RI involves continuous vaccine services, while SIAs, or preventive campaigns, aim to reach a large number of people from a target population in a short period of time. SIAs are planned according to disease-specific programmes, including eradication programmes (Global Polio Eradication Initiative (GPEI), Measles \& Rubella Initiative (MRI) following specific guidelines (WHO Regional office Africa, 2015)). The dynamics between RI and SIAs differ significantly: RI is a generic, efficiency-oriented immunisation strategy that leads to stable population protection, whereas SIAs aim to quickly elevate immunisation levels. Both RI and SIAs are included in the NIP and require the supply, distribution and administration of vaccines, which are performed partly by the same actors and partly by dedicated actors, both included in the Planned immunisation.
Emergency immunisation is driven by a different paradigm: reaction to minimise damage. Actors, resources, and policies differ as well, since international emergency response is guided by IHR and WHO-led emergency decision frameworks (World Health Organization, 2017) for vaccination in acute humanitarian emergencies. Equally as in the case of domestic emergency response, the approach is campaign-based and much more time-limited and case and disease-specific, and it has a higher degree of uncertainty, such as the timely securing of vaccines from emergency stockpiles.

Although Planned and Emergency Immunisation act as complementary mechanisms, Planned Immunisation is preferred since it efficiently prevents VPD cases and strengthens the population health status in accordance with the SDGs. When it comes to priority setting and funding allocation, however, it is shown that treatment of patients typically prevails over prevention (Bishai et al., 2014; Tversky \& Kahneman, 1974). To counteract this, the WHO/ UNICEF-EPI programme fosters the GVAP and the DoV acceleration plans with adequate funding from GAVI and other donors. These plans have successfully separated decisions on national Immunisation plans from other health care decisions and enabled LMIC governments to commit to immunisation. The required vaccination coverage targets for most pathogens lead to herd immunity. When the coverage level drops below this threshold it leads to outbreaks and activates the need for emergency immunisation.

The risk of a VPD outbreak depends on the combined epidemiological risk factors having an effect at the community level. Vaccination coverage, living conditions, exposure to pathogens and previous infections at the local level amongst others can deviate dramatically from the district or national average levels.

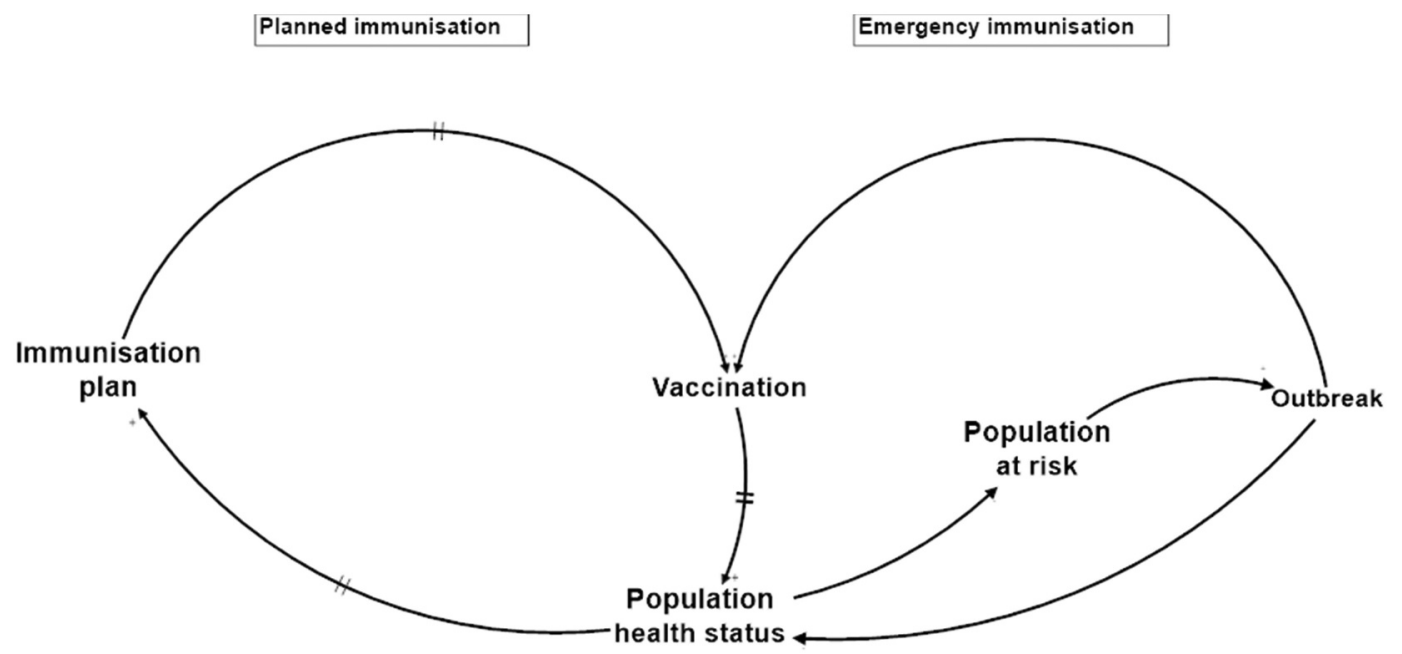

Figure 2. Aggregated system diagram highlighting two paradigms: planned and emergency immunisation. 


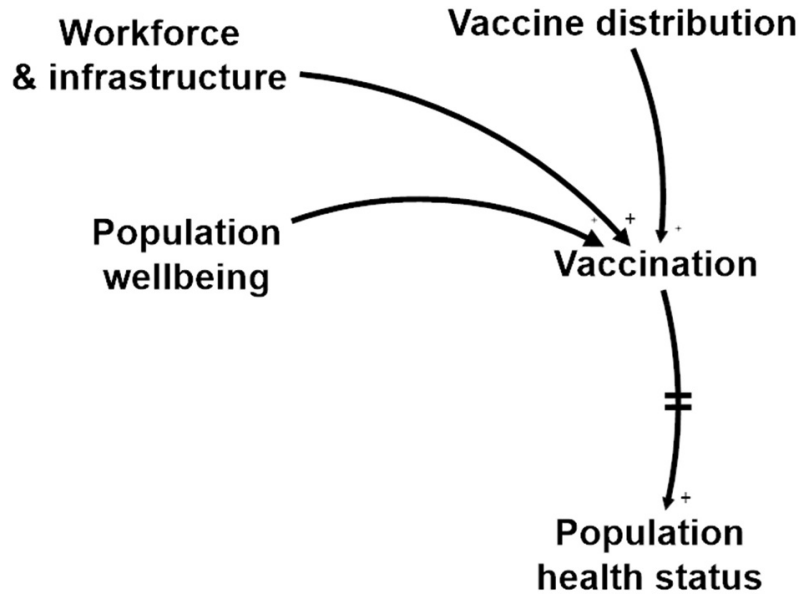

Figure 3. Three flows that need to be synchronised for high IMS performance, make up the focal point of the IMS: Child (Population wellbeing), Nurse (Workforce \& infrastructure), and Vaccine (Vaccine distribution).

Planned and Emergency immunisation are usually designed and modelled in a different context: the former in the framework of health systems strengthening and disease-specific programmes (including eradication), the latter in outbreak response (including humanitarian operations). However, a systems perspective inevitably leads to their connection points where they impact each other on their need for local resources and their effect on Vaccination and Population Health.

\subsubsection{Three flows - vaccinee, vaccinator and} vaccine

Vaccination is the central point where a healthy person receives a potent vaccine administered by a skilled health professional. These three flows need to converge at the right moment in order to generate the desired immune response, both in planned and emergency immunisation, as shown in Figure3. The location may be fixed (at a HC), outreach or mobile. To this end, vaccines are carefully transported to the vaccination point, nurses are trained and need to be available, vaccination sessions are organised and the mothers or targeted populations attend the sessions, sometimes invited by community health workers.

\subsubsection{Six loops}

In order to capture the main underlying mechanisms that govern the human-made IMS and the natural system of disease transmission, six feedback loops were introduced in the IMS diagram, as indicated in Figure 4 and explained in Table 2. In the Planned immunisation part of the system, Vaccination is at the intersection of three feedback loops, each of them including one of the three flows: (R1) the Population wellbeing loop (child), (R2) the Workforce and Infrastructure loop (nurse), and (R3) the Vaccine supply loop (vaccine). At the Emergency immunisation side of the system, two feedback loops represent the immunisation of people at risk before a wider outbreak occurs (Surveillance and response loop, B1), or during an outbreak which could not be controlled by the national IMS (Outbreak response immunisation loop, B2). Finally, an Outbreak feedback loop shows disease spreading among people at risk during an outbreak (R4). Evidently, this diagram is layered with respect to the individual pathogens and is connected through several shared system elements. A brief explanation of the loops can be found in Table 2, and details are explained in Annexe 1.

The IMS diagram was created to facilitate systemsbased stakeholder engagement by representing the previously identified and generally acknowledged, underlying mechanisms in LMICs' immunisation systems. When stakeholders see the structure of the IMS, it helps them to get oriented and to

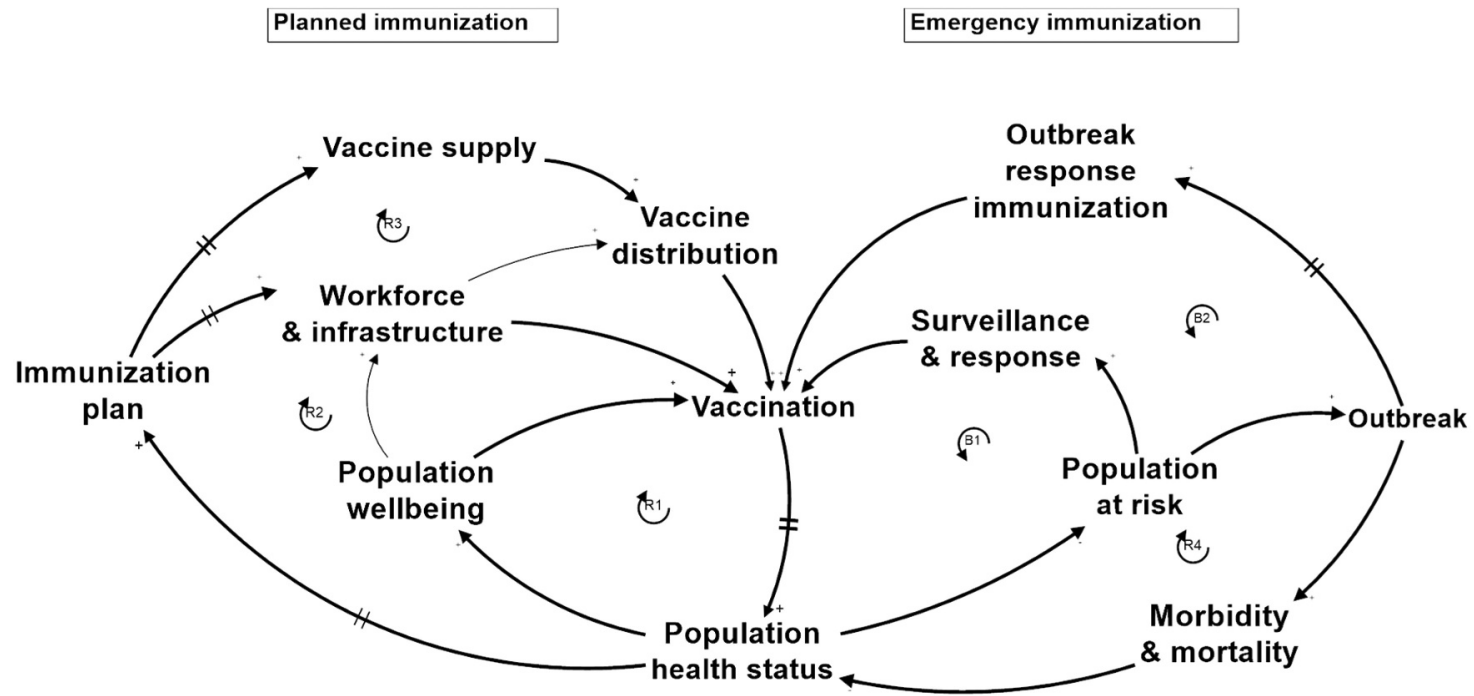

Figure 4. IMS diagram: Aggregated causal-loop diagram of IMS in a LMIC. Applicable to national, subnational level and local settings. 
Table 2. Brief explanation of the feedback loops in the IMS diagram. A detailed explanation can be found in Annexe 1.

\section{R1 population wellbeing loop Vaccination - Population health status - Population wellbeing - Vaccination}

R2 Workforce and infrastructure loop

Vaccination - Population health status - Immunisation plan Workforce \& infrastructure - Vaccination

\section{R3 Vaccine supply loop}

Vaccination - Population health status - Immunisation plan and infrastructure -

Vaccination

\author{
B1 Outbreak prevention loop \\ Vaccination - \\ Population health status - \\ Population at risk - \\ Surveillance \& response - Vaccination
}

R4 Outbreak loop

Population health status - Population at risk - Outbreak -

Morbidity and mortality - Population health status

\section{B2 Outbreak response loop}

Vaccination - Population health status - Population at risk -

Outbreak - Outbreak response immunisation - Vaccination
Vaccination improves Population health status over time which increases Population wellbeing. Higher wellbeing leads to higher access to vaccination.

Vaccination improves immunisation coverage levels leading to less vaccinepreventable disease cases and higher Population health status over time. Higher Population health status requires less resources for catch-up immunisation, and more room for improving immunisation services (e.g., by increasing workforce skills and capacity) and their coverage (e.g., with outreach services) which both take several years to effectively impact vaccination services.

Vaccination improves immunisation coverage levels leading to less vaccinepreventable disease cases and higher Population health status over time. Higher Population health status requires less resources for catch-up immunisation, and leaves room for expanding the schedule with additional vaccines (e.g., against HPV, COVID-19) or booster doses throughout the population's lifetime to further reduce the national burden of disease and to respond to evolving epidemiology.

Vaccination improves protection against vaccine-preventable diseases (VPDs) and Population health status which reduces the Population at risk of getting VPDs. A higher Population at risk leads to more disease cases that need to be identified via surveillance systems and more execution of response immunisation campaigns to prevent outbreaks. More campaigns lead to more vaccinations.

Lower Population health status increases Population at risk of getting a vaccine preventable disease. Higher Population at risk increases the probability and size of Outbreaks which increase Morbidity and mortality numbers due to the VPD. These numbers directly reduce Population health status indicators.

Lower Vaccination reduces Population health status over time and increases Population at risk. Higher Population at risk increases the probability and size of Outbreaks which require more Outbreak response immunisation, which manages to increase Vaccination. complement the systems diagram with countryspecific and disease-specific elements to build an IMS map or a system dynamics model. As a consequence, the IMS diagram needs to be intuitive and easily understandable, and therefore it represents the absolute basic mechanisms governing the IMS of most LMICs. This entailed removing limiting loops that did not play a dominant role in the current LMICs' reality as expressed by the stakeholders during the activities that led to the creation of the IMS diagram. It also led to leave out loops that express the context-dependent demand factors such as population growth rate or migration flows, (re)emerging pathogens and disease prevalence spread. To trigger the co-creation of a complete model with stakeholders, the IMS diagram was complemented with sustainability and resilience factors (as will be shown later in Figure 7), which largely connect to these missing loops.

Furthermore, the actors in the IMS diagram can represent subsystems, which consist of a number of stocks, flows, and levels. For instance, immunisation plan represents the adequacy of the National Immunisation Plan which aims to close the gap between the vaccination need and vaccination services offered. This subsystem consists of flows, such as the yearly resources allocated to vaccine procurement, infrastructure, and human resources, and the domestic and external funding that feeds the plan.

\subsection{Application of the IMS diagram as a tool for system redesign}

The application of the systems approach framework based on the IMS diagram is illustrated as a threephased iterative process: (1) creation of a shared insight on how the IMS works, (2) evaluation of current system performance, sustainability and resilience, and (3) directions for sustainable and resilient system redesign.

\subsubsection{Shared system insight}

The redesign process first involves stakeholder identification (Decouttere et al., 2016). The IMS diagram facilitates this by providing a generic framework for stakeholder selection to engage in group model workshops and co-creation sessions (Figure 5). Each system element in the IMS diagram represents specific stakeholders. By inviting stakeholder subsets from different levels in Rwanda and Kenya to collectively clarify the system's working and performance, shared insights arose and the stakeholders' mental models were broadened and refined, similar to the findings of Kopainsky et al. (2017). Firstly, a system-level insight gained was the enhanced awareness of the child, nurse and vaccine flow synchronisation, and its impact on planning and evaluating the interventions, including demand generation. Secondly, the long delays, causing rigidity and potential instability in the vaccine supply 


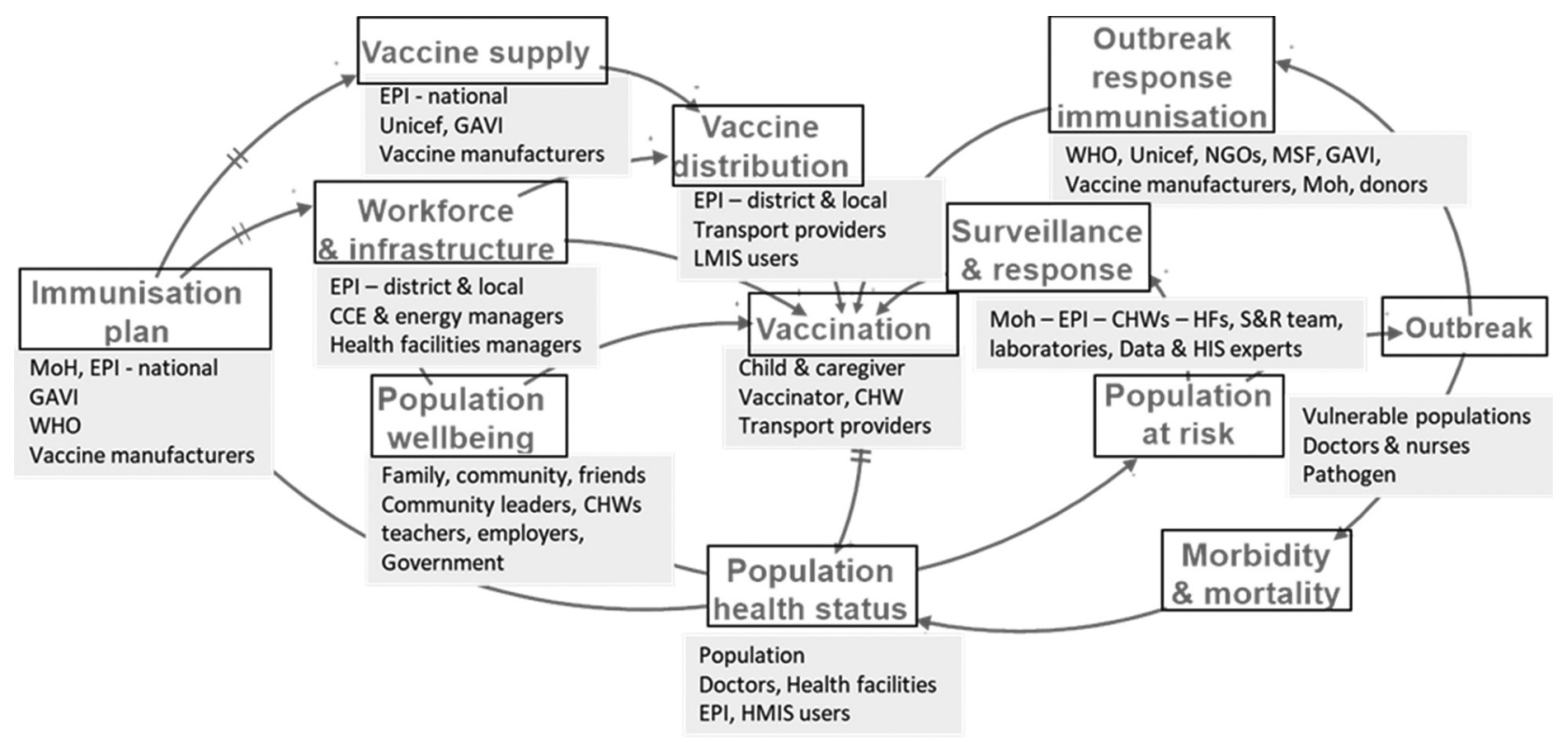

Figure 5. Stakeholders mapped on the generic LMIC IMS diagram.

chain, were pointed out. Thirdly, the role of human decision-making and the adaptive behaviour of the system was regarded to broadly impact the performance of the system, and seemed to culminate at the point of vaccination.

\subsubsection{Current system assessment}

Starting from behaviour-over-time graphs related to Vaccination and Population Health Status, the stakeholders in Rwanda and Kenya were triggered to recall their experiences and share their perspectives on the factors driving the current system. A structured discussion supported by the IMS diagram yielded the following three main insights. First, the different contextual factors at the local level and the resulting disparities in local vaccination coverage and health outcomes confirmed the need to refine system design below the national level. Using the IMS diagram as a template for mapping different local contexts with their versions of dominating feedback loops, proved to be a powerful communication tool that drew attention to the contrasting elements. A typical example is the different accessibility issues in a remote rural setting and a densely populated urban setting. Second, the limited availability of local patient-based data is further complicated by population mobility based on a free choice of health care. The difficult vaccination demand assessment and vaccination coverage monitoring require greater flexibility at the $\mathrm{HCs}$ and demand generation by Community Health Workers (CHWs). The granularity of the data does not correspond to the scale of the problem and structural data deficiencies, such as the Denominator error, are attributed to an inaccurate target population number. Third, basic mechanisms behind system challenges were often diverse and distant, both in space and time, from the observed issues. A low measles vaccine stock level at a district hospital could be caused by higher demand due to an unforeseen campaign, recently increased local demand, a new measles vaccine introduction, a new and learning EPI responsible, or a supply problem at the manufacturer level.

The assessment at the local level is illustrated by a typical rural and semi-urban setting, derived from cases in Rwanda and focusing on measles. Figure 6 shows clear differences between the two settings. On the one hand, the rural setting suffered from low access to the HC due to poverty (R1) and insufficient coverage of health services in the area (R2). In addition, the growing population at risk remained invisible to the surveillance and response team (B1) until an outbreak occurred (R4) leading to disease cases and deaths, which eventually triggered local outbreak response immunisation (B1). A large epidemic requiring a nationwide intervention could be avoided (B2). On the other hand, the peri-urban setting had high coverage of HCs, and the population visited their preferred HC. This led to unpredictable demand, requiring a flexible vaccine stock management at the HC (R3). Due to economically driven population mobility and lack of patientbased immunisation data available to the $\mathrm{HC}$, the local immunisation coverage rate was unknown and individual measles cases popped up (R1). The surveillance and response team could intervene adequately (B1) and was able to prevent the 

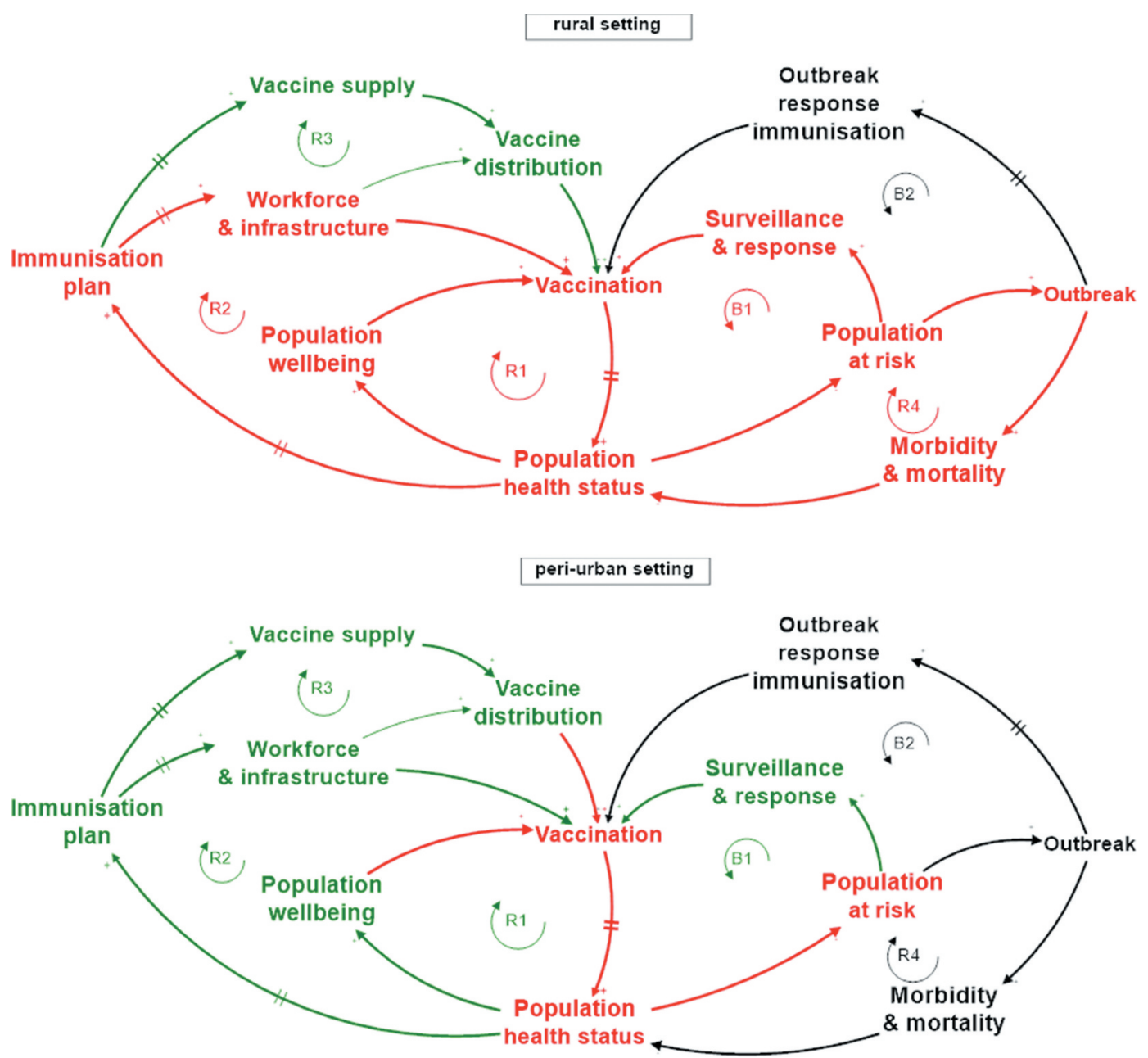

Figure 6. System assessment of local settings derived from cases in Rwanda: rural area (top) and peri-urban area (bottom) with respect to measles. Mechanisms that are active, are shown as red or green loops when they have a, respectively, negative or positive impact on the IMS performance. Mechanisms that are not active at the moment of assessment, such as international emergency immunisation mechanisms (B2), are shown as black loops on the IMS model.

emergence of an outbreak, which would have triggered accelerated disease transmission (R4) and potentially required outbreak response immunisation (B2).

Technically, the sustainability assessment of the IMS means investigating whether the Planned immunisation loops R1/R2/R3 and the Outbreak prevention loop B1 are capable of dominating the system until 2030 and beyond. The Population at risk should be kept small enough such that the surveillance and response mechanisms can avoid outbreaks. Achieving this status requires an IMS that continuously provides the right antigens needed to protect the target population from the VPDs they potentially get exposed to, in a timely and inclusive manner.

In order to assess the long-term dominance of loops $\mathrm{R} 1 / \mathrm{R} 2 / \mathrm{R} 3$ and $\mathrm{B} 1$, the factors constraining them must be identified. This requires a structured investigation of the actual status and future evolution of the IMS actors that keep the loops running and, equally important, the exogenous constraining factors. For example, $\mathrm{R} 1$ depends on (1) health-seeking behaviour, (2) vaccinating with the setting-specific vaccines to combat U5MR, and (3) favourable economic conditions fostering well-being. The loops R2, R3 and B1 heavily depend on the adequacy of the Immunisation plan, which in turn cannot be attained without government and donor commitment (Figure 7). The latter is exogenous, but known future evolutions like GAVI graduation can be explicitly taken into account when designing feasible transition scenarios incorporating increased domestic funding.

The evolution of Vaccine Manufacturing and Vaccine Development, the other exogenous factors driving R3, depends on the global vaccine market and the vaccine development outcomes for new pathogens.

Further exogenous factors impacting current and future demand for immunisation are (1) Climate change, causing reduced population health status and higher exposure to pathogens and (2) Migration and its impact on population growth. Furthermore, the rise of non-communicable diseases (NCDs) and the Demographic shift in SSA will change the role of the 


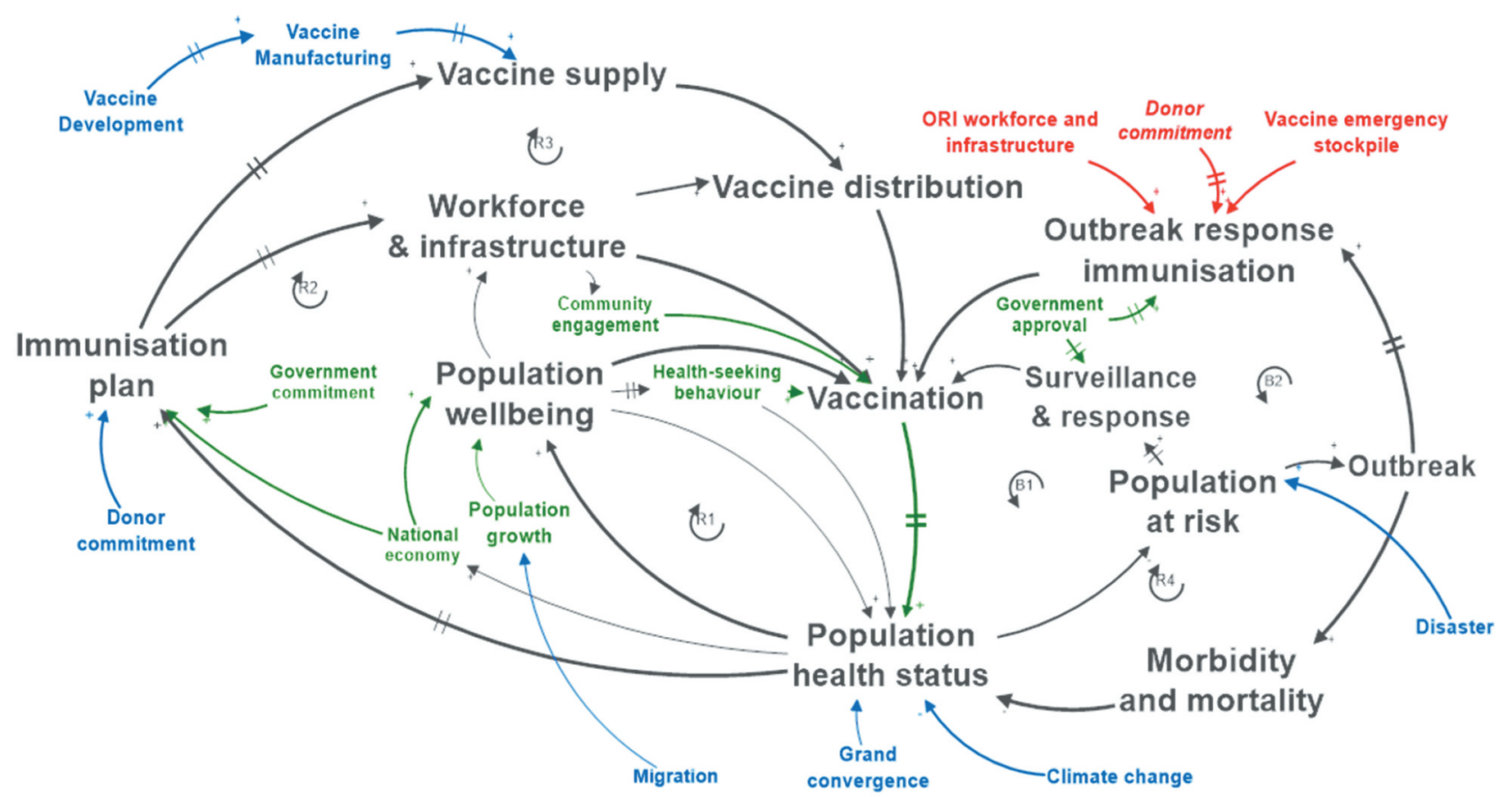

Figure 7. Factors determining sustainability of the IMS: endogenous factors (green) and exogenous factors (blue). Exogenous resilience factors of the IMS are red.

IMS in healthcare systems. The impact of all these combined elements must be understood in order to design sustainable IMSs.

When these factors evolve disruptively, the system's resilience is challenged. From the IMS diagram, the following resilience phases can be recognised: (1) prevention: the degree to which loops R1/R2/R3 manage to avoid the creation of a population at risk, (2) mitigation: the effect of loop B1 to avoid or to reduce the impact of a potential outbreak, (3) response: as the activation of loop B2 during an outbreak in R4, (4) recovery: the time and effort it takes to restart the stable mode with loops R1/R2/R3 dominating, and (5) adaptation: the improvements that make the IMS better equipped to cope with the next disruptive event or chronic stress.

As a consequence, the resilience of the IMS varies according to the disease type considered, the system scale, and the specific geographical setting. On top of that, the performance of loop B2 depends heavily on exogenous factors such as the timely distribution of emergency stockpiles and the availability of ORI workforce and infrastructure from humanitarian organisations. The rural setting in Figure 6 lacked resilience, while the peri-urban setting showed adequately resilient behaviour.

\subsubsection{Directions for system redesign}

Once the underlying mechanisms are identified, interventions at leverage points can be generated. Some leverage points could be identified by stakeholders during workshops and feedback meetings (activities
2 and 6 from Table 1). Potential leverage points of an IMS, classified according to the Intervention-Level Framework (Malhi et al., 2009; Meadows, 1999), are listed in Table 3.

The upper categories Table 3, such as Paradigms and Goals, are deep leverage points: they have a transformative and long-lasting impact but are hard to implement. Shallow leverage points such as structural elements are easier to implement but have a local, short-term effect. Shallow leverage points act predominantly on one subsystem or loop, e.g., the vaccine supply loop $\mathrm{R} 3$. The more interlinkages with other subsystems, the higher the transformational power of the leverage point. In the rural setting in Figure 6, examples of potential interventions, at each level, are: additional staff at the nearest HC (L5), outreach vaccination at the community (L4), sustainable community-specific immunisation programme, e.g., self-sustained mobile clinic (L3), IMS goals for inclusivity at the same level as national coverage (L2), and reaching a level of social cohesion preventing communities/individuals to fall behind (L1).

In this way, the potential impact of interventions and the implementation path can be modelled qualitatively. When appropriate for decision-making, a numerical simulation model at (sub)national scale can be derived from the fine-tuned IMS diagrams, which structure the complex system to be simulated. This is particularly the case if the leverage point would be located in the vaccine supply (Figure 4) where aspects of home-grown solutions and local manufacturing are possible interventions. This will conversely 
Table 3. Examples of immunisation system leverage points classified according to Malhi et al. (2009) based on Meadows (1989).

\begin{tabular}{|c|c|}
\hline Intervention level & IMS Leverage points and potential directions of change \\
\hline 1. Paradigm & $\begin{array}{l}\text { - Expanding the mindset behind the IMS: from the anthropocentric ethic of preventive health as an enabler } \\
\text { for human wellbeing, to the One Health/Planetary Health concept: Multi-stakeholder health approach } \\
\text { (human, animal, environment) (Whitmee et al., 2015) } \\
\text { - Emergence instead of centrally controlled system: Social cohesion as cornerstone of health-seeking } \\
\text { behaviour (Ubuntu) (Barugahare, 2018) }\end{array}$ \\
\hline 2. Goals & $\begin{array}{l}\text { Complement IMS targets based on SDG3, IHRs and national immunisation targets with targets addressing } \\
\text { - Vulnerable groups and geographic diversity } \\
\text { - Sustainability targets beyond financial sustainability } \\
\text { - Differentiation based on transdisciplinary thinking }\end{array}$ \\
\hline $\begin{array}{l}\text { 3. System structure (across IMS loops } \\
\text { and outside IMS) }\end{array}$ & $\begin{array}{l}\text { Self-Organising power } \\
\text { - Country-specific IMS, adapted to local circumstances } \\
\text { - Self-Organisation at subnational level: counties, districts, health centres } \\
\text { Rules of the system } \\
\text { - Planned and emergency immunisation as one holistic system } \\
\text { - Synchronisation at vaccination point: differentiation, effectiveness, efficiency } \\
\text { - Community engagement, CHWs connecting immunisation demand and supply } \\
\text { - National immunisation programme adequacy and funding sustainability } \\
\text { Information flows } \\
\text { - Patient-based data, real-time vulnerability maps available to health workers } \\
\text { - Patient-based health information available to population for fostering personal and community health } \\
\text { - Supply-related data available to relevant stakeholders }\end{array}$ \\
\hline 4. Feedback and delays & $\begin{array}{l}\text { Reinforcing feedback loops } \\
\text { - Efficiency of vaccine supply loop: vaccine wastage reduction } \\
\text { - Efficiency and effectiveness of workforce and infrastructure loop } \\
\text { - Strength of wellbeing loop, linked to education and poverty } \\
\text { - Balancing feedback loops } \\
\text { - Interface between national and international response to epidemics } \\
\text { - Immunisation delivery options with different dynamics: Rl, campaigns } \\
\text { - Delays in outbreak prevention loop and outbreak response loop } \\
\text { - Synchronisation of vaccine supply and distribution delays to create stability in the system }\end{array}$ \\
\hline $\begin{array}{l}\text { 5. Structural elements (within IMS } \\
\text { loops) }\end{array}$ & $\begin{array}{l}\text { - Vaccine Supply chain network layout } \\
\text { - Size of warehouses and vaccine inventory levels } \\
\text { - Workforce capacity }\end{array}$ \\
\hline
\end{tabular}

lead to better economic conditions and consequently improved population health status and lower disease prevalence.

A time-dependent implementation roll-out plan for a single intervention or combination of interventions constitutes an intervention scenario. Depending on the system scale, intervention scenarios appear in the health sector strategic plans, whereas the intervention implementation is captured in the cMYP, district plans or operational plans at the HC level.

For the design of sustainable intervention scenarios, one can rely on (1) the knowledge that interventions at deep leverage points determine the system within which shallow leverage points operate and (2) the concept of human-centred design to understand and model the needs and the adaptive behaviour of stakeholders. Furthermore, redesign of the IMS needs to consider the temporal aspect as the system changes constantly and reaching a sustainable synchronising of the three flows will require a best-fit of the IMS to its evolving environment and circumstances.

In summary, the framework can be applied to the design of interventions and scenarios related to (1) subsystems' structure (e.g., vaccine distribution), (2) interventions across subsystems (e.g., target setting) and (3) interventions at the boundary of the IMS (e.g., integration of immunisation with other systems).

\section{Discussion}

Without requiring a systems background, the IMS diagram guides stakeholders, including policymakers, along the feedback loops and paradigms that make up the complexity of an IMS. The aggregated level invites stakeholders to use the diagram as a template, providing them with the necessary system elements to capture their mental models, generate high-leverage interventions and allow them to adapt their behaviour and decisions (Rouwette et al., 2010). In this way, the conceptual model represents a problem-structuring step in iterative system design processes and exposes the need for long-term decision-making and political commitment. Moreover, the framework allows us to connect findings from the literature (e.g., vaccine supply chain optimisation models) with implementation research (indicating contextual circumstances and implementation pathway).

The proposed approach may be extended and applied to preventive health systems beyond immunisation and to infectious diseases which are not yet vaccine-preventable (e.g., malaria, HIV, TB).

The notion of sustainability has been translated into systems behaviour, feedback loop dominance and the evolution and impact of constraining factors. All these elements indicate whether the system 
is capable of evolving along with its environment to continue to fulfil its purpose in the long run. Therefore, designing for sustainability not only involves financial sustainability and increasing efficiency but also challenges the boundaries of the IMS and considers interventions at deep leverage points. This creates options such as integration with preventive health systems (e.g., nutrition, family planning), interactions at the interface between immunisation and other health subsystems (investment in immunisation means treatment savings), the evolution of population growth (linked to family planning, economic development, education, migration), and the continued vaccine availability and affordability. Additionally, long-term phenomena become relevant such as immune protection waning, pathogen resistance, climate-change induced disease spreading, and development of new vaccines. The design of well-coordinated sustainable response interventions requires a broader perspective related to the position of humans in the ecosystem, which goes beyond the scope of this study. The integration of family planning and immunisation in one single model is a future research direction by which we want to understand the levels at which sustainable scenarios for a population health status can be obtained and if these levels are consistent with the findings of an existing socio-economic planning model such as the T21 model (Pedercini et al., 2019).

Similar to sustainability, system resilience was analysed through systems behaviour. However, the time span of dynamic behaviour linked to disruptive events and resilience is much shorter (weeks or months) compared to evolutions linked to sustainability (years or decades). When the IMS is pushed to its limits, its response (loops B1 and B2) is impacted by contextual factors and effective human decision-making. To fully embrace resilience in the IMS design, the transition of loop dominance from outbreak response to outbreak prevention and to planned immunisation for emerging diseases should be investigated. Alternatively, in the case of COVID-19, the exogenous factor of vaccine development dominates the IMS performance in the initial stages. Furthermore, the interplay between planned immunisation and emergency immunisation opens up new ways to combine their design options to jointly achieve better immunisation performance. This has not been exploited to its full potential up to now. Areas include for instance, innovative types of campaigns, active engagement of target population(s) in communities, temporary settlements and mobile populations, and integration of health-promoting services. Moreover, one could consider to aim beyond the observed immunisation need to create an "overly" preventive state of the system in which additional gains to health, or wellbeing, could be reached from a feedforward loop.

As each country has its own history and unique political, social, economic and environmental background, the country-specific IMS has evolved and adapted to disruptive events. Many learnings, valuable for future IMS design, can be found by analysing IMSs within their specific context. Examples are the organisation of community health services in Rwanda or devolution of health care in Kenya. Additionally, this opens the door for cross-border collaboration around shared health threats, such as expanding disease vector habitats or migration of infected people.

This research provides a tool to investigate whether and how to push forward deep leverage points, as an answer to the call for sustainable IMS design. It enables to go beyond the redesign within one subsystem, and to focus on their interaction and the cornerstones of immunisation, such as routine immunisation, emergency response, separating EPI from health care, availability of patient-based data and community engagement.

Limitations to this research include the number of countries and settings that served as the basis for the systems diagram, and the selection of system's concepts illustrated in this paper. We plan to include this in our future research. Additionally, an in-depth investigation of delays identified in the IMS loops, and their contribution to oscillatory behaviour, deserves more attention in the future research.

\section{Conclusion}

This research intended to provide a systems-inspired framework to support the design of sustainable and resilient IMS for LMICs. Resulting from IMS stakeholder engagements, an aggregated IMS diagram was developed and applied for the assessment of immunisation performance, and for the identification of current and future challenges together with their underlying mechanisms. Finally, system leverage points for IMSs were introduced to guide design directions for intervention scenarios leading to IMS sustainability and resilience.

The study delivered the following insights:

The stakeholder-supported IMS diagram successfully uncovers the relation between IMS interventions and health outcomes, both on national and local levels.

In order to redesign a more efficient, resilient and sustainable IMS, two paradigms, planned and emergency immunisation, should be considered as part of one IMS.

The synchronisation of three flows (child, nurse, vaccine), represented by three feedback loops, is key to IMS performance. 
The concepts of system sustainability and resilience are translated into tangible system actors and behaviour.

A structured method was proposed to derive intervention scenarios from the conceptual IMS diagram. Consequently, the framework can be applied as a problem structuring tool as part of the system design process.

The discussion of the role and integration of immunisation in the broader preventive health systems contributing to universal health coverage, and the broader IMS sustainability dimensions were not further explored in this paper and are part of future research.

\section{Acknowledgments}

We would like to thank the two anonymous reviewers for their valuable inputs that greatly helped to improve this work.

\section{Disclosure statement}

No potential conflict of interest was reported by the authors.

\section{Funding}

This work was supported by the GlaxoSmithKline [Research Chair on Access to Medicines]; Fonds Wetenschappelijk Onderzoek [PhD Fellowship: project number $1113720 \mathrm{~N}$ ].

\section{ORCID}

Catherine Decouttere (D) http://orcid.org/0000-0003-47261729

\section{References}

Adam, T., \& de Savigny, D. (2012). Systems thinking for strengthening health systems in LMICs: Need for a paradigm shift. Health Policy and Planning, 27 (suppl4), iv1-iv3. https://doi.org/10.1093/heapol/czs084

Adamu, A. A., Sarki, A. M., Uthman, O. A., Wiyeh, A. B., Gadanya, M. A., \& Wiysonge, C. S. (2019). Prevalence and dynamics of missed opportunities for vaccination among children in Africa: Applying systems thinking in a systematic review and meta-analysis of observational studies. Expert Review of Vaccines, 18(5), 547-558. https://doi.org/10.1080/14760584.2019.1588728

Agyepong, I. A., Sewankambo, N., Binagwaho, A., CollSeck, A. M., Corrah, T., Ezeh, A., Fekadu, A., Kilonzo, N., Lamptey, P., Masiye, F., Mayosi, B., Mboup, S., Muyembe, -J.-J., Pate, M., Sidibe, M., Simons, B., Tlou, S., Gheorghe, A., Legido-Quigley, H., Ng, E., ... Piot, P. (2017). The path to longer and healthier lives for all Africans by 2030: The Lancet Commission on the future of health in sub-Saharan Africa. The Lancet, 390(10114), 2803-2859. https://doi. org/10.1016/S0140-6736(17)31509-X

Auping, W. L., Pruyt, E., \& Kwakkel, J. H. (2017). Simulating endogenous dynamics of intervention-capacity deployment: Ebola outbreak in
Liberia. International Journal of Systems Science: Operations \& Logistics, 4(1), 53-67. https://doi.org/10. 1080/23302674.2015.1128576

Baltussen, R., Jansen, M. P. M., Bijlmakers, L., Grutters, J., Kluytmans, A., Reuzel, R. P., Tummers, M., \& Der Wilt, G. J. V. (2017). Value assessment frameworks for HTA agencies: The organization of evidence-informed deliberative processes. Value in Health, 20(2), 256-260. https://doi.org/10.1016/j.jval.2016.11.019

Barasa, E., Mbau, R., \& Gilson, L. (2018). What is resilience and how can it be nurtured? A systematic review of empirical literature on organizational resilience. International Journal of Health Policy and Management, 7(6), 491-503. https://doi. org/10.15171/ijhpm.2018.06

Barugahare, J. (2018). African bioethics: Methodological doubts and insights. BMC Medical Ethics, 19(1), BioMed Central Ltd. https://doi.org/10.1186/s12910-018-0338-6

Bazos, D. A., LaFave, L. R. A., Suresh, G., Shannon, K. C., Nuwaha, F., \& Splaine, M. E. (2015). The gas cylinder, the motorcycle and the village health team member: a proof-of-concept study for the use of the Microsystems Quality Improvement Approach to strengthen the routine immunization system in Uganda. Implementation Science : IS, 10(1), 30. https://doi.org/10.1186/s13012-015-0215-3

Bishai, D., Paina, L., Li, Q., Peters, D. H., \& Hyder, A. A. (2014). Advancing the application of systems thinking in health: Why cure crowds out prevention. Health Research Policy and Systems, 12(1), 28. https://doi.org/10.1186/ 1478-4505-12-28

De Boeck, K., Decouttere, C., \& Vandaele, N. (2020). Vaccine distribution chains in low- and middle-income countries: A literature review. Omega, 97, 102097. https:// doi.org/10.1016/j.omega.2019.08.004

Decouttere, C., Vandaele, N., Lemmens, S., \& Bernuzzi, M. (2016). The vaccine supply chain multathlon: The reconciliation of technology, economy and access to medicines. In C. W. Zobel, N. Altay, \& M. P. Haselkorn (Eds.), ADVANCES IN MANAGING HUMANITARIAN OPERATIONS (Vol. 235, pp. 205-227). Springer. https://doi.org/10.1007/978-3-31924418-1_10

Duijzer, L. E., van Jaarsveld, W., \& Dekker, R. (2018). Literature review: The vaccine supply chain. European Journal of Operational Research, 268(1), 174-192. https://doi.org/10.1016/j.ejor.2018.01.015

GAVI The Vaccine Alliance. (2019). Gavi 5.0 strategy 20212025.

Golding, N., Burstein, R., Longbottom, J., Browne, A. J., Fullman, N., Osgood-Zimmerman, A., Earl, L., Bhatt, S., Cameron, E., Casey, D. C., DwyerLindgren, L., Farag, T. H., Flaxman, A. D., Fraser, M. S., Gething, P. W., Gibson, H. S., Graetz, N., Krause, L. K., Kulikoff, X. R., \& Hay, S. I. (2017). Mapping under-5 and neonatal mortality in Africa, 2000-15: A baseline analysis for the sustainable development goals. The Lancet, 390 (10108), 2171-2182. https://doi.org/10.1016/S01406736(17)31758-0

Gonçalves, P. (2011). Balancing provision of relief and recovery with capacity building in humanitarian operations. Operations Management Research, 4(1-2), 39-50. https://doi.org/10.1007/s12063-011-0045-7

Gooding, E., Spiliotopoulou, E., \& Yadav, P. (2019). Impact of vaccine stockouts on immunization coverage in Nigeria. Vaccine, 37(35), 5104-5110. https://doi.org/10. 1016/j.vaccine.2019.06.006 
Haidari, L. A., Brown, S. T., Wedlock, P., Connor, D. L., Spiker, M., \& Lee, B. Y. (2017). When are solar refrigerators less costly than on-grid refrigerators: A simulation modeling study. Vaccine, 35(17), 2224-2228. https://doi. org/10.1016/j.vaccine.2016.11.103

Hovmand, P. S. (2014). Community based system dynamics. Springer New York. https://doi.org/10.1007/978-1-46148763-0

Kawakatsu, Y., \& Honda, S. (2012). Individual-, family- and community-level determinants of full vaccination coverage among children aged 12-23 months in western Kenya. Vaccine, 30(52), 7588-7593. https://doi.org/10.1016/j. vaccine.2012.10.037

Kopainsky, B., Hager, G., Herrera, H., \& Nyanga, P. H. (2017). Transforming food systems at local levels: Using participatory system dynamics in an interactive manner to refine small-scale farmers' mental models. Ecological Modelling, 362, 101-110. https://doi.org/10.1016/j.ecol model.2017.08.010

Larson, H. J., Clarke, R. M., Jarrett, C., Eckersberger, E., Levine, Z., Schulz, W. S., \& Paterson, P. 2018. Measuring Trust in Vaccination: A Systematic Review. Human Vaccines \& Immunotherapeutics,14(7), 1599-1609. https://doi.org/10.1080/21645515.2018.1459252

Lee, B. Y., Mueller, L. E., \& Tilchin, C. G. (2017). A systems approach to vaccine decision making. Vaccine, 35(supplement 1), A36-A42. https://doi.org/10.1016/j.vaccine. 2016.11.033

Lemmens, S., Decouttere, C., Vandaele, N., \& Bernuzzi, M. (2016). A review of integrated supply chain network design models: Key issues for vaccine supply chains. Chemical Engineering Research \& Design, 109, 366-384. https://doi.org/10.1016/j.cherd.2016.02.015

Malhi, L., Karanfil, O., Merth, T., Acheson, M., Palmer, A., \& Finegood, D. T. (2009). Places to intervene to make complex food systems more healthy, green, fair, and affordable. Journal of Hunger \& Environmental Nutrition, 4(3-4), 466-476. https://doi.org/10.1080/ 19320240903346448

Meadows, D. H. (1999). Leverage points places to intervene in a system. The Sustainability Institute.

Meadows, D. H., \& Wright, D. (2008). Thinking in systems : A primer (D. Wright, Ed.). Chelsea Green Publishing.

Ndwandwe, D., Uthman, O. A., Adamu, A. A., Sambala, E. Z., Wiyeh, A. B., Olukade, T., Bishwajit, G., Yaya, S., Okwo-Bele, J. M., \& Wiysonge, C. S. (2018). Decomposing the gap in missed opportunities for vaccination between poor and non-poor in sub-Saharan Africa: A multicountry analyses. Human Vaccines \& Immunotherapeutics, 14(10), 2358-2364. https://doi.org/ $10.1080 / 21645515.2018 .1467685$

Ozawa, S., Paina, L., \& Qiu, M. (2016). Exploring pathways for building trust in vaccination and strengthening health system resilience. BMC Health Services Research, 16(S7), 639. https://doi.org/10.1186/s12913-016-1867-7

Pedercini, M., Kleemann, H. M., Dlamini, N., Dlamini, V., \& Kopainsky, B. (2019). Integrated simulation for national development planning. Kybernetes, 48(1), 208-223. https://doi.org/10.1108/K-11-2017-0440

Pertet, A. M., Kaseje, D., Otieno-Odawa, C. F., Kirika, L., Wanjala, C., Ochieng, J., ... Odindo, D. (2018). Under vaccination of children among Maasai nomadic pastoralists in Kenya: is the issue geographic mobility, social demographics or missed opportunities? BMC Public Health, 18(1), 1-9. https://doi.org/10.1186/s12889-0186309-5
Plotkin, S., Robinson, J. M., Cunningham, G., Iqbal, R., \& Larsen, S. (2017). The complexity and cost of vaccine manufacturing - An overview. Vaccine, 35(33), 40644071. https://doi.org/10.1016/J.VACCINE.2017.06.003

Remme, J. H. F. F., Adam, T., Becerra-Posada, F., D’Arcangues, C., Devlin, M., Gardner, C., Ghaffar, A., Hombach, J., Kengeya, J. F. K. K., Mbewu, A., Mbizvo, M. T., Mirza, Z., Pang, T., Ridley, R. G., Zicker, F., \& Terry, R. F. (2010). Defining research to improve health systems. PLoS Medicine, 7(11), e1001000. https://doi.org/10. 1371/journal.pmed.1001000

Rouwette, E. A. J. A., Korzilius, H., Vennix, J. A. M., \& Jacobs, E. (2010). Modeling as persuasion: The impact of group model building on attitudes and behavior. System Dynamics Review, 27(1), 1-21. https://doi.org/10. 1002/sdr.441

Rouwette, E. A. J. A., Vennix, J. A. M., \& Felling, A. J. A. (2009). On evaluating the performance of problem structuring methods: An attempt at formulating a conceptual model. Group Decision and Negotiation, 18(6), 567-587. https://doi.org/10.1007/s10726-007-9100-z

Rwashana, A. S., Nakubulwa, S., \& Adam, T. (2016). Applying a system dynamics modelling approach to explore policy options for improving neonatal health in Uganda. Health Research Policy and Systems, 14(1), 35. https://doi.org/10.1186/s12961-016-0101-8

Sarley, D., Mahmud, M., Idris, J., Osunkiyesi, M., DibosaOsadolor, O., Okebukola, P., \& Wiwa, O. (2017). Transforming vaccines supply chains in Nigeria. VACCINE, 35(17), 2167-2174. https://doi.org/10.1016/j. vaccine.2016.11.068

Sterman, J. (2000). Business dynamics : Systems thinking and modeling for a complex world. Irwin/McGraw-Hill.

Tversky, A., \& Kahneman, D. (1974). Judgment under uncertainty: Heuristics and biases. Science, 185(4157), 1124-1131. https://doi.org/10.1126/science.185.4157.1124

UN. (n.d.). SUSTAINABLE DEVELOPMENT GOAL 3. https://sustainabledevelopment.un.org/sdg3

United Nations Inter-agency Group for Child Mortality Estimation. (2018). Levels \& Trends in Child Mortality Report 2018.

Wedlock, P. T., Mitgang, E. A., Haidari, L. A., Prosser, W., Brown, S. T., Krudwig, K., Siegmund, S. S., DePasse, J. V., Bakal, J., Leonard, J., Welling, J., Steinglass, R., Mwansa, F. D., Phiri, G., \& Lee, B. Y. (2018). The value of tailoring vial sizes to populations and locations. Vaccine, 37(4), 637-644. https://doi.org/10.1016/j.vac cine.2018.12.010

Whitmee, S., Haines, A., Beyrer, C., Boltz, F., Capon, A. G., de Souza Dias, B. F., Ezeh, A., Frumkin, H., Gong, P., Head, P., Horton, R., Mace, G. M., Marten, R., Myers, S. S., Nishtar, S., Osofsky, S. A., Pattanayak, S. K., Pongsiri, M. J., Romanelli, C., \& Yach, D. (2015). Safeguarding human health in the Anthropocene epoch: Report of the Rockefeller foundation-lancet commission on planetary health. The Lancet, 386(10007), 1973-2028. https://doi.org/10.1016/S01406736(15)60901-1

WHO | The Alliance for Health Policy and Systems Research (AHPSR). (2019). WHO; World Health Organization. https://www.who.int/alliance-hpsr/en/

WHO Regional office Africa. (2015). African regional guidelines for measles and rubella surveillance.https://www. afro.who.int/sites/default/files/2017-06/who-africanregional-measles-and-rubella-surveillance-guidelines_ updated-draft-version-april-2015_1.pdf . 
WHO-Unicef. (2019). WHO vaccine-preventable disease monitoring system, 2019 global summary.

World Health Organization (WHO). (2018). WHO guideline on health policy and system support to optimize community health worker. Geneva. https://apps.who. int/iris/bitstream/handle/10665/275474/9789241550369eng.pdf?ua $=1$

World Health Organization. (2017). Vaccination in acute humanitarian emergencies: Framework for decision-making. http://apps.who.int/iris/bitstream/ 10665/255575/1/WHO-IVB-17.03-eng.pdf?ua=1

World Health Organization (WHO), \& Centers for Disease Control and Prevention (CDC). (2010). Technical guidelines for Integrated Disease Surveillance and Response in the African Region.

World Health Organization (WHO). (2016). International Health Regulations. (2005). WHO Library (3rd ed.).

World Health Organization. 2020. Immunization Agenda 2030: A global strategy to leave no one behind.https:// www.who.int/teams/immunization-vaccines-and-biolo gicals/strategies/ia

Yadav, P. (2015). Health product supply chains in developing countries: Diagnosis of the root causes of underperformance and an agenda for reform. Health Systems \& Reform, 1(2), 142-154. https://doi.org/10.4161/23288604. 2014.968005

\section{Annexe 1 Description of the six feedback loops}

(R1) The Population Wellbeing loop (VAC - PHS PWE - VAC)

Population Health Status is positively impacted by the number of fully immunised children by means of Vaccination. The strength of this causal effect is determined by vaccine efficacy, immunological response, vaccination coverage at the community scale, and exposure to the pathogen. The effect is limited to the extent that vaccine-preventable diseases represent only part of the morbidity and mortality observed. Increased childhood vaccination is the consequence of more surviving children in the birth cohort and net immigration. Both effects are linked to population wellbeing. Access to immunisation is, in many LMIC settings, linked to the distance to the health centre, road accessibility, the cost of transportation, the education level of the caregiver, and the rank of the child in the family (Kawakatsu \& Honda, 2012; Pertet et al., 2018), all elements that are positively linked to Population Wellbeing. Under the Reaching Every District (RED) programme, outreach activities have significantly been strengthened (Bazos et al., 2015; World Health Organization, 2017a). Even with secured access, the ultimate decision for a child to get vaccinated is made by the caregiver, driven by her/ his Health-seeking behaviour, observed as vaccine hesitancy. This dependency on individual human decisionmaking is the bedrock of the need for human-centred design. The positive feedback loop is closed by the generally acknowledged relation between Population Wellbeing and Population Health Status.
(R2) Workforce and infrastructure loop (VAC PHS - IP - WIF - VAC)

Starting from Population Health Status, the same path to Vaccination is followed as in R1. In order for Vaccination to take place, a skilled vaccinator with sufficient time available to vaccinate and to manage vaccine inventories needs to be present. The vaccinator needs a data management system for vaccination coverage tracking and vaccine ordering, an accessible health centre equipped with cold-chain infrastructure, transportation and equipment for outreach activities. The Workforce and Infrastructure dedicated to the EPI resorts under the responsibility of the Ministry of Health $(\mathrm{MoH})$. The budget, strategies and interventions are planned in the national Immunisation Plan and, when properly done, result in better performance of the Workforce and Infrastructure. The restricted availability of skilled health professionals and recruitment delay adds rigidity to this loop, as well as staff retention and continued training. Similar issues are faced by the CHWs: as CHWs have access to detailed information about vaccine demand in the community, they are able to directly influence the access to immunisation. Their motivation, related to recognition, material, and financial working conditions, is, therefore, a key element (World Health Organization (WHO), 2018). Again we underscore the human-centred design aspect by the crucial role of human decision-making in the hands of the immunisation workforce and the local community. The link between the Immunisation plan and the Population Health Status indicates that delivering an adequate Immunisation plan is more likely when the Population Health Status is already at a good level. With herd immunity or disease eradication already achieved, it is easier to establish a feasible Immunisation plan to further improve the Population Health Status. In contrast, a lower Population Health Status represents more considerable immunisation challenges that need to be addressed and a delay between the Population Health Status and the Immunisation plan exists as it takes time to collect and report the Population Health Status indicators such as U5MR and to plan strategies that act upon them.

\section{(R3) Vaccine supply loop (VAC - PHS - IP - VSU -} VDI - VAC)

Upstream from the point of Vaccination in de CLD, the third element needed is the vaccine. Vaccine availability relies on the Vaccine distribution network performance, from the point of entry to the point of vaccination. The Vaccine distribution network includes the cold-chain equipment and multiple transportation modes down to all levels where fixed vaccination and outreach take place.

Through the entire journey, the volume of vaccines, the vaccine quality, and required cold-chain conditions are managed, guided by EPI procedures and WHO/UNICEF inventory guidelines. Product wastage due to expiry, cold-chain excursions, and unused doses in multi-dose vials are monitored. Thanks to continued focus and support from the LMIC governments, GAVI and WHO/UNICEF and many implementing organisations, vaccine availability has increased while logistics cost and vaccine wastage are kept under control. The biggest challenge remains the last mile, where local infrastructural 
conditions play a huge role and where multiple health-systems strengthening programmes have fuelled innovative interventions. This is expressed by the causal relation between Workforce \& Infrastructure and Vaccine distribution.

Vaccine distribution performance in the country depends on a reliable Vaccine supply to the LMIC. Since the beginning of IMSs, Vaccine supply has been the main concern that triggered actions of donor organisations. This concern is grounded in (1) Vaccine manufacturing (the limited availability of some vaccines) and (2) the LMICs' ability to procure the vaccines. The first concern is caused by the complex vaccine production process, the high-quality requirements and the long production lead time (Plotkin, Robinson, Cunningham, Iqbal, \& Larsen, 2017). In addition, Vaccine development is costly and takes years, and so does the production facility construction and the approval process. Given the limited number of vaccine manufacturers and the constrained global vaccine production capacity, shortages occur. The availability of vaccines lies clearly beyond the control of individual SSA LMICs and global initiatives have been taken to further develop the vaccine market and to support production of vaccines in LMICs. The mechanism behind this is exogenous to the LMIC immunisation system. The mechanism behind this is exogenous to the LMIC IMS. The second concern related to the affordability of vaccines for LMICS, has been countered by GAVI's vaccine funding mechanism. This mechanism supports eligible LMICs with vaccine co-financing and price negotiations. Therefore, an adequate Immunisation plan contains a solid vaccine funding plan, in line with the expected need for vaccines. The mechanism behind Donor commitment is exogenous to the LMIC system, but Government commitment is endogenous and its relation to the Immunisation Plan is part of the system to be understood and redesigned. Related to the Immunisation Plan, it is part of the system redesign exercise. At this point, important indications of sustainability are the fraction of domestically financed vaccines and the existence of a feasible transition scenario upon GAVI graduation.

\section{(B1) Outbreak prevention loop (VAV - PHS - PAR -} OPI - VAC)

Outbreak prevention immunisation is the last option to uplift low Vaccination levels to avoid outbreaks among the Population at risk. Outbreak prevention immunisation relies on a wellfunctioning infectious disease Surveillance \& response (IDSR) mechanism that detects and reports cases of epidemic-prone diseases as soon as the disease-specific alert threshold is reached. If the threshold is surpassed, response actions are activated. Campaigns triggered by the IDSR team that need to be carried out urgently are not foreseen in the NIP and may cause disruptions to the IMS, potentially harming RI activities. The latter needs to be minimised to improve resilience.

\section{(B2) Outbreak response loop (VAC - PHS - PAR - $O B K$ - ORI - VAC)}

The outbreak response loop is triggered by an Outbreak among the Population at risk that cannot be controlled by the national IMS. The first type of outbreak occurs when herd immunity is lost, as the outbreak could not be prevented by the planned immunisation loops R1/R2/R3 and
Outbreak prevention loop B1. Depending on the disease, the outbreak size and the community setting, case management and immunisation activities are planned according to $\mathrm{WHO}$ epidemic preparedness and response guidelines. Coordination of Outbreak response immunisation lies with the country-level EPI staff, supported by UNICEF and NGOs if needed, or at the international level in case of a pandemic.

A second type of outbreak occurs when immunisation coverage levels were sufficiently high and the outbreak was thus not expected. The root cause can lie elsewhere: (1) the adaptive behaviour of the pathogen, (2) unobserved weaknesses in the IMS such as coverage inequity or (3) the presence of high-risk groups or undetected cases in the population. Each of these root causes urge to investigate their root causes and to improve the IMS, the vaccines, or the health system responsible for case management. These are opportunities to adapt the system to build resilience.

A third type of outbreak occurs as part of a larger public health emergency following a disaster or humanitarian crisis, for example, a cholera outbreak after a flooding. The planned IMS system has not failed in its preventive performance, but the occurrence and impact of this type of outbreaks could have been smaller if the health system had been more resilient. The antigens needed in this case are usually not included in the RI schedule (e.g., oral cholera vaccine) and need to be supplied as soon as possible. The time between the detection and the first Outbreak response immunisation needs to be minimised, considering the acceleration of disease cases in the Outbreak loop. Therefore, routine procurement, production and shipping lead times do not apply. Instead, a rapid supply of vaccines during major outbreaks can be obtained through various channels: UNICEF for several childhood vaccinations; GPEI for polio; MRI for measles or rubella; the International Coordinating Group on Vaccine Provision (ICG) for meningitis, yellow fever or cholera vaccines; the Humanitarian Mechanism for pneumococcal vaccine (World Health Organization, 2017); CEPI for NTDs or delivered directly from vaccine manufacturers' stockpiles. Furthermore, country approval and customs' clearance constitute potential delays, human resources have to be mobilised, and cold-chain equipment must be available. In order to minimise the delay before the start of an Outbreak response immunisation campaign, the different potential causes of delay must be tackled in parallel.

\section{(R4) Outbreak loop (PHS - PAR - OBK - MMT - PHS)}

When Population health status is low and a critical group of people becomes susceptible and exposed, the Outbreak loop is activated and evolves according to the disease-specific epidemiological pathways. Typically, as more people get infected, contact with other people further spreads the disease. This disease transmission mechanism will continue as long as there is a group of susceptible people in the Population at risk. Therefore, it is paramount that the outbreak loop is counterbalanced by the Outbreak response immunisation loop B2 as soon as the former is activated. 